\title{
El arte de gobernar un Gobierno Autómono Descentralizado es, primero, un problema conceptual
}

The Art of Governing an Autonomous Decentralized Government $(G A D)$ is First a Conceptual Problem

A arte de governar um Governo Autônomo Descentralizado (GAD) é primeiro um problema conceitual

\author{
Edison Mafla \\ Universidad Andina Simón Bolívar, Sede Ecuador \\ edison.mafla@uasb.edu.ec
}

DOI: https://doi.org/10.32719/25506641.2019.5.8

Artículo de opinión

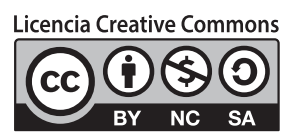


L

a palabra gobierno proviene de la raíz griega dirigir, su traducción más cercana se refiere al arte del timonel, en un sentido más mecánico, como conducir un auto, maniobrar un bote u operar un tablero de mando, es decir, una serie de toma de decisiones para que el trabajo se resuelva de acuerdo al objetivo y funcionalidad de la máquina. El gobierno nacional o local, en la actualidad, propone una concepción democrática y participativa, que va más allá de lo mecánico; y también se considera como un arte, uno que implica la concreción del Estado y la identificación de las relaciones de poder que en este existen.

En las pasadas elecciones, llevadas a cabo en marzo de 2019, se eligieron 5.675 autoridades para los niveles de gobierno provincial (23 provincias), un régimen especial en Galápagos, cantonal (221 cantones) y parroquial (823 parroquias); en total, alrededor de diez mil servidores públicos ocuparán puestos de alta dirección. ¿Están claros todos ellos cómo dirigir el gobierno autónomo descentralizado (GAD) de su correspondiente circunscripción? ¿Acaso no es un problema conceptual saber cómo gestionar dentro de su entidad, a su población con la diversidad de actores públicos y privados; incluso más allá de sus límites territoriales?

El gobierno, la gobernabilidad y la gobernanza en este sentido se vuelven factores fundamentales y a la vez complejos; en su definición y en las formas cómo estas se presentan, dónde se aplican, quiénes son los que intervienen y cómo sus políticas públicas son coherentes y de impacto para propiciar un desarrollo integral en sus pobladores y territorio; o existe una fórmula para gobernar, por lo que es indispensable debatir los conceptos para que, desde la autoridad elegida por votación popular, se conciba la responsabilidad suficiente de administrar el poder y alcanzar un nivel deseable de gobernabilidad, referido particularmente enfocado a conciliar y gestionar el nivel político y administrativo al interior del GAD; de igual forma se debe concebir los sistemas de relaciones con todos los actores externos al gobierno local con quienes se genere niveles óptimos de gobernanza, es decir, a las formas 
eficientes y efectivas de permanente diálogo, negociación y sobre todo inclusión en la toma decisiones sobre la política pública del gobierno local.

Según Bracamonte (2002, 73), "Los fines del Estado son la seguridad y derechos fundamentales, orden y justicia, se realizan con los medios que tienen el gobierno que son la fuerza, el poder político y la autoridad. El gobierno se encarga a través de un grupo de personas, de la administración del Estado, origina lo que se denomina la administración pública y el desarrollo de una burocracia". El gobierno, en el sentido antes expuesto, tiene una característica que dinamiza la administración estatal a través de la fuerza que da el poder político y la autoridad. Complementando esta idea se cita la proyección del gobierno referida por Sanabria $(2007,155)$, "Respecto al concepto de gobierno, recordando la destacada obra de Fayol, que se refiere a la marcha efectiva de la organización como un todo hacia sus objetivos, así como su adecuada proyección en el entorno y el tiempo". Recogiendo estas primeras ideas, vemos que gobierno es el ejercicio de administrar y gestionar el poder y las relaciones, a través del poder político de la autoridad, en este caso de la autoridad local, propiciando que la institucionalidad tenga objetivos y directrices claras, que se ajustan a las condiciones, contextos y coyunturas de su circunscripción territorial.

A propósito de estas primeras afirmaciones se puede identificar que la institucionalidad misma es el Estado y el gobierno está a su servicio; puede darse un cambio de gobierno a través de las elecciones, mas no un cambio de Estado, para ello debe plantearse una reforma desde la propia Constitución del país, lo cual resultaría más complejo; por tanto, es importante recordar lo que Hobbes $(2000,74)$ hace muchos años pensó sobre el Estado:

Dícese que un Estado ha sido instituido cuando una multitud de hombres convienen y pactan, cada uno con cada uno, que a un cierto hombre o asamblea de hombres se le otorgará, por mayoría, el derecho de representar a la persona de todos (es decir, de ser su representante). Cada uno de ellos, tanto los que han votado en pro como los que han votado en contra, deben autorizar todas las acciones y juicios de ese hombre o asamblea de hombres, lo mismo que si fueran suyos propios, al objeto de vivir apaciblemente entre sí y ser protegidos contra otros hombres.

El pacto en sí mismo ya es un ejercicio que implica diálogo y acuerdos enfocados en este caso a los objetivos de desarrollo de un territorio, es decir, pensando el bien común. Con las distintas acepciones de gobierno, destaca- 
mos este último como el servicio que el gobierno debe entregar al Estado, específicamente: fuerza, poder político y autoridad, enfocados hacia los objetivos colectivos y no a los intereses particulares. La actual Constitución de la República del Ecuador (EC 2008), específicamente en el artículo 1 del Código Orgánico de Organización Territorial, Autonomía y Descentralización (COOTAD 2008), determina el modelo de administración, descentralización y desarrollo que los GAD, en el marco de la planificación y otras regulaciones del Estado del nivel nacional, deben tener:

Art. 1. Ámbito.- Este Código establece la organización político-administrativa del Estado ecuatoriano en el territorio: el régimen de los diferentes niveles de gobiernos autónomos descentralizados y los regímenes especiales, con el fin de garantizar su autonomía política, administrativa y financiera. Además, desarrolla un modelo de descentralización obligatoria y progresiva a través del sistema nacional de competencias, la institucionalidad responsable de su administración, las fuentes de financiamiento y la definición de políticas y mecanismos para compensar los desequilibrios en el desarrollo territorial.

Los GAD son personas jurídicas de derecho público, con autonomía política, administrativa y financiera. La normativa particular indica que están integrados por las funciones de participación ciudadana de legislación y fiscalización y, ejecutiva previstas en el COOTAD y en su estatuto de autonomía, para el ejercicio de las funciones que le corresponden.

El gobierno engloba los conceptos de gobernanza y gobernabilidad, estos son indispensables; ninguno es más que el otro. La gobernabilidad tiene distintos momentos históricos. Conforme las perspectivas teóricas fueron evolucionando, y aunque fue considerado un concepto ambiguo, difuso y hasta difícil de operacionalizar hace algunos años, en la actualidad existen varias definiciones que permiten no solo afinar el concepto, sino, además, identificar mecanismos y procedimientos efectivos para su implementación y evaluación.

Para Vásquez (2014, 63), "La gobernabilidad es atributo de los sistemas sociopolíticos (y por extensión económicos) caracterizados por su capacidad de formular e implementar decisiones públicas, es decir, de transformar las demandas o preferencias ciudadanas en políticas concretas". Este sin duda es el preámbulo para hablar de gobernanza porque se empieza a definir el camino hacia como se deben marcar las estrategias y vinculaciones con los otros actores; sin embargo y para no alejarse del concepto de gobernabilidad 
es importante determinar en qué escenario del gobierno local se empiezan a diseñar las políticas públicas, en dónde y cómo se recoge la información suficiente para establecerlas.

Vásquez destaca la gobernabilidad en el nivel subnacional como un resultado del proceso de reforma del Estado. Haciendo una referencia al continente latinoamericano, los autores hacen un hincapié en la participación en el fortalecimiento y organización del gobierno. En esa línea Vásquez (2014, 64) indica: "La nueva gobernabilidad local ha impulsado al mercado y a la redes de política pública como formas de organización del gobierno local, generándose con ello un nuevo proceso de formulación de políticas públicas, sustentado en la participación ciudadana y caracterizado por la existencia de múltiples lógicas de acción". Estos modelos de gobierno que son propiciados por la nueva gobernabilidad local prevista por Vásquez, ¿se han consolidado o no en nuestros gobiernos locales, sobre todo aquella que implica ese acercamiento a la sociedad civil a través de su participación?

Para Prats (2001, 103): "La gobernabilidad local debe ser entendida, esencialmente como gobernabilidad urbana, esto implica la necesidad de generar las capacidades necesarias para formular estrategias y agendas compartidas de ciudad o ciudad-región y de aplicarlas en el entornos dinámicos y cambiantes como lo son, los centros urbanos". Es decir, las estrategias de gestión y administración recaerían en el nivel ejecutivo; las discusiones políticas que se dan en los consejos o juntas, en el nivel legislativo, donde se regula y fiscaliza el uso adecuado de los recursos públicos; siendo en el nivel técnico el espacio donde se ajustan las decisiones de manera operativa para su debido aterrizaje, dejándolas listas para confrontarlas con la ciudadanía y otras entidades públicas y privadas del territorio donde se implementarán las propuestas de desarrollo local o política pública local.

Estas capacidades estratégicas que se generan al interior del gobierno y que ayudan a fortalecer el Estado cuentan con una forma de gestión externa importante y es el segundo concepto que complementa al gobierno. La gobernanza, si bien es una tarea de diálogo, negociación e inclusión con otros actores distintos a la institución del GAD, son actores públicos o privados que viven, invierten y se desarrollan en las circunscripciones territoriales que administra el GAD. 
Mayorga y Córdova (2007) en su obra Gobernabilidad y gobernanza en América Latina analizan varios autores que destacan elementos importantes que permitirán desarrollar una concepción integral sobre gobernanza. Una primera idea gira en torno a consolidar los consensos y garantizar la estabilidad de las políticas públicas; para ello, Celedón afirma que es importante contar con actitudes y valores institucionales como la transparencia de los procesos y mecanismos de control social complementarios a lo que hacen otros órganos de control público o privados. Jolly (2001) indica que es necesario conocer -examinar- las interrelaciones de la sociedad civil, el Estado y el mercado, ya que no es importante lo que se decide sino el cómo, por tanto el contexto y la cultura de un territorio también son un factor que, si bien se analiza en el componente de la gobernabilidad, en la gobernanza es importante que ese diagnóstico se valide y socialice con los actores externos, ya que esto conllevaría que las decisiones tomadas por la autoridad local además cuenten con principios que fortalezcan la democracia local y, sobre todo, desde el ejercicio de la gobernanza se propicie una lucha contra la corrupción, lo que implicará que cada gobernante prevea formas innovativas de inclusión de la sociedad civil.

Hablar de gobernanza nos acerca a lo que prevé Balbis, referido al deber ser y al abordar la política alejada de las percepciones clásicas del análisis político y jurídico del Estado, es decir, nos lleva a explorar desde el deber ser de la norma -en materia pública se hace estrictamente lo que determine la ley- y también desde la potencialidad del territorio tanto de sus recursos como de sus actores, ya que para Balbis el Estado no es el único ni el principal actor del desarrollo y es un actor que debe potenciarse: son justamente aquellos que giran alrededor del mercado (empresa, instituciones, e individuos, consumidores y productores), y, por lo general, en un territorio se cuenta con organizaciones no gubernamentales como cooperativas, fundaciones, sindicatos, mutualistas, organizaciones comunitarias, clubes sociales, deportivos, etc.

Con la gobernanza como un supuesto de avanzar hacia unas mejores dinámicas de relación horizontal y vertical tanto con otros actores institucionales como otros (actores sociales, políticos, económicos y/o comunitarios), el diálogo con todos los actores resulta una estrategia importante, ya que de allí se propician los acuerdos y cambios en las prácticas y principios sociales, se 
mejora la confianza de su población provocando legitimidad en las acciones públicas.

Esta confianza está depositada en gran parte en el proceso de descentralización que aún se está generando en el país; de hecho, el Ecuador ha promovido la descentralización por más de 30 años; en este sentido, para Delamaza, Cunill y Joignant $(2012,3)$, se puede conseguir la confianza de un territorio cuando en este se aplican adecuada y ajustadamente sus competencias:

Este enfoque es particularmente aplicable a los problemas vinculados a la descentralización y el desarrollo territorial, como es posible evidenciarlo a través del desarrollo de las principales dimensiones asociadas a las redes como forma de regulación social y la gobernanza como expresión política, estableciendo el vínculo existente entre estas y el territorio.

Si bien una fórmula de gobernar no existe, las diferentes concepciones nos llevan a determinar que Bracamonte no solo hace bien en particularizar el Estado y el gobierno como unidad, sino que los considera un complemento, que permite la viabilidad del poder político y que con esto se lleva a consolidar la administración pública. En el caso de los gobiernos locales a través de su arquitectura organizacional (gestión interna) no solo pretende un incremento de su burocracia; particularmente, busca su desarrollo para que sean estos quienes puedan ayudar a promover una cultura de participación con todos los protagonistas del desarrollo (gestión externa) en la construcción de la política pública local.

A partir de lo mencionado, nos acercamos a entender la necesidad de considerar la gobernabilidad y la gobernanza como medios idóneos para fortalecer el gobierno, en este caso el gobierno local, que no depende de sus actuaciones de sus territorios y en la medida que estos se consoliden se podría avanzar a incorporar otros elementos del desarrollo como, por ejemplo, la globalización, ya que sus efectos producen nuevos roles y relaciones entre los diversos actores del desarrollo; consecuentemente, deviene la modernización del Estado.

Ahora bien, si además introducimos la globalización dentro de los conceptos gobierno, gobernabilidad y gobernanza, la misma puede consolidar o lesionar la estructura de la propia gobernabilidad; para Vargas $(2005,9)$, 'La 
globalización ha limitado las oportunidades de desarrollo de las economías más frágiles, debilitado y socavado las bases del poder de los Estados nacionales, aumentando las tensiones sociales y por tanto la gobernabilidad de las sociedades.

Según Navarro $(2002,1)$, "Los gobiernos locales han experimentado un cambio en la misma dirección forzados por retos como: La competencia política, la territorialización de las políticas públicas, las reformas institucionales en la gestión públicas y los desafíos que tienen en sí las democracias representativas". En la medida en que se abordan diversos ámbitos de la labor gubernamental o de las relaciones entre Estado y sociedad, y aún de la realidad social en sentido general, las definiciones varían en una proporción similar a la diversidad de temas.

Sin embargo, se puede afirmar que la gobernabilidad y gobernanza como concepto es aplicable en la medida en que esta se adscriba conscientemente al ciclo de la gestión pública y la implementación de las políticas públicas, incluyendo la sociedad civil (sector privado, organizaciones de la sociedad civil, cooperación internacional, barrios y comunidades de su territorio), poniendo a la autoridad local en la necesidad de contar con cuadros competentes y sensibles que, por un lado, administren eficientemente los recursos públicos, a la vez que sintonicen con las demandas ciudadanas y propicien espacios y mecanismos de participación para su desarrollo local.

En este marco los desafíos que se presentan para los GAD son que estos tienen que velar principalmente por la inversión eficiente de los fondos públicos, la gestión transparente de sus recursos, así también de la democratización y socialización de la política ecológica, social y económica de sus territorios.

Todos estos esfuerzos podrían perderse en una serie de acciones sin sentido, por tanto, la gobernabilidad y la gobernanza deben ser elementos fundamentales para nuestros gobernantes. En las elecciones de marzo de 2019, según el Consejo Nacional Electoral, se eligieron a 5.675 autoridades principales; por tanto, es importante asegurar el timón. Dicho de otra manera, asegurar el gobierno, ya que la primera puerta a cruzar es la gobernabilidad, la que asegurará una adecuada legislación entre disensos y consensos, en pensar que lo técnico puede subordinarse a lo político para determinar estrategias de implementación de la política pública. Con estas claves funda- 
mentales se abrirá paso a la siguiente puerta, la de la gobernanza, generando principalmente las alianzas debidas (principios de asociatividad, y relaciones multinivel) que permitan que la estrategias políticas que nacieron de los planes de campaña se cristalicen una vez más con la participación ciudadana para la definición de sus planes de desarrollo y ordenamiento territorial; y que este sea la brújula para todas estas interacciones que aseguren el compromiso de las organizaciones sociales, el sector público y privado para su efectiva concreción y control. Estos conceptos fundamentales interiorizados conscientemente, con ética pública y trasparencia, fortalecerán lo que buscamos todos los mandantes en su mandatario: que cuente con "El arte de gobernar".

\section{Referencias}

Bracamonte, Eduardo. 2002. "Política, estado y gobierno". Revista Ciencia y Cultura, No. 10: 73-78.

Delamaza, Gonzalo, Nuria Cunill y Alfredo Joignant. 2012. Nueva agenda de descentralización en Chile. Santiago: Ril Editores.

Hobbes, Thomas. 2000. El Estado. Ciudad de México: Fondo de Cultura Económica.

Jolly, Jean-François. 2001. "Región y descentralización: enfoque económico versus enfoque político". Ponencia realizada en el Seminario Nacional Lo Regional en la Colombia del siglo XXI". Consulta: abril de 2019. 〈https://presupuestosparticipativos.com/wp-content/ uploads/2016/12/los_publico_y_lo_local_Jolly.pdf〉.

Mayorga, Fernando, y Eduardo Córdova. 2007. "Gobernabilidad y gobernanza en América Latina”. Documento de trabajo. Ginebra. Consulta: abril de 2019. «ttp://www.institut-gouvernance.org/es/analyse/fiche-analyse-334.html .

Navarro, Carmen. 2002. "Gobernanza en el ámbito local". Ponencia presentada en el VII Congreso Internacional del CLAD sobre la reforma del Estado y de la Administración Pública. Lisboa. Consulta: abril de 2019. 〈http://unpan1.un.org/intradoc/groups/public/documents/ CLAD/clad0043412.pd .

Prats, Joan. 2001. "Gobernabilidad democrática para el desarrollo humano. Marco conceptual y analítico". Instituciones y desarrollo, No. 10: 103-148.

Sanabria, Mauricio. 2007. "De los conceptos de administración, gobierno, gerencia, gestión y management: algunos elementos de corte epistemológico y aportes para una mayor comprensión”. Unidad \& Empresa 6, No. 13: 155-194. 


\section{Edison Mafla}

Vargas, José. 2005. "Transformación de la gobernabilidad económica global. Problemas del desarrollo". Revista Latinoamericana de Economía 23, No. 142: 9-26.

Vásquez, María, y Marcela Navarrete. 2014. "La gobernabilidad local en el contexto de la nueva gestión pública”. Luna Azul, No. 39: 63-88. 